7th International Conference on Building Resilience; Using scientific knowledge to inform policy and practice in disaster risk reduction, ICBR2017, 27 - 29 November 2017, Bangkok, Thailand

\title{
Governance and recovery: comparing recent disaster recoveries in Sri Lanka and New Zealand
}

\author{
Morten Gjerde ${ }^{\mathrm{a}} \&$ Shenuka de Sylva ${ }^{\mathrm{a}}$.
}

${ }^{a}$ Victoria University of Wellington, New Zealand

\begin{abstract}
Governance is understood to have considerable influence on the success of recoveries following a natural disaster. What constitutes good governance and successful recovery in these circumstances? This question is discussed in relation to two recent recovery processes. Sri Lanka has, for all intents and purposes, recovered from the tsunami that struck there and other parts of southern Asia in 2004. Christchurch, New Zealand was devastated by a sequence of earthquakes during 2010 and 2011 and recovery there is now well under way. The paper discusses the governance structures that have guided these two recoveries. While it is understood that the effects of disasters could potentially be life long and recovery from them complex, compatibility of the process and outcomes in relation to cultural norms and the critical issue of housing are the key issues discussed across the two cases.
\end{abstract}

(C) 2018 The Authors. Published by Elsevier Ltd.

Peer-review under responsibility of the scientific committee of the 7 th International Conference on Building Resilience.

Keywords: Sri Lanka; Christchurch; Disaster Recovery; Recovery Governance

\section{Introduction}

It is understood that governance and leadership will have considerable influence on the outcomes of rebuilding and recovery efforts following unexpected natural disasters. While the literature around disaster recovery continues to grow, significant gaps in our understanding of just how governance affects recovery remain [1]. This can in part be attributed to the fact that each recovery is unique, with a broad range of possible influences. Case studies can therefore

\footnotetext{
* Corresponding author. Tel.: +64-4-463-6063; fax: +64-4-463-6204.

E-mail address: shenuka.desylva@vuw.ac.nz
} 
be useful for highlighting important issues, particularly when comparisons are made. This paper discusses efforts to rebuild the areas affected by the 2004 tsunami event in Sri Lanka and the 2010-2011 earthquakes that struck the city of Christchurch, New Zealand. While acknowledging the devastation caused to people, their economies and social infrastructure, these events also created opportunities for improvement. In addressing how well these opportunities have been capitalized on, this paper contextualizes reconstruction efforts in their social, political and economic circumstances. The research is informed by the stakeholder interviews, post-occupancy evaluation and expert analysis carried out by the authors. It is further developed with reference to literature that focusses on aspects of each recovery, and that concerned with governance issues.

Post disaster recoveries are characterized by uncertainty, particularly as people's expectations and the influence of market forces cannot be predicted. These vary according to the local culture, resource availability, economic influences, and capacity. Two factors in rebuilding success after a disaster are the speed with which it takes place and the quality of the outcomes $[1,2]$. These are closely linked and changes in one will generally lead to changes in the other, particularly when costs are also considered [3]. However, recovery should also account for the psychological and socio-cultural interests of affected communities [4, 5]. Given these broad aims, priorities must be struck between matters such as housing, infrastructure replacement, economic development and building community resilience. The best way to lead recovery processes in such variable circumstances is complex, but should be addressed in light of the marked increases in disaster related damage in the developed and developing worlds.

\section{Recovery in Sri Lanka}

In the immediate aftermath of the Boxing Day Tsunami, which killed more than 37,000 people and displaced over a million more in 12 of Sri Lanka's 14 coastal districts [6], people found shelter with family, friends and strangers and in temples, churches and schools. Relief and rescue efforts commenced before the initial shock wore off, before detailed reports of the devastation spread, and before the arrival of international humanitarian aid. The protracted civil war came to a halt as both factions put aside decades of differences to focus on rebuilding the nation. Conflict, ethnic and religious differences and economic disparity were forgotten as assistance in the form of medical personnel, manpower, food, water, clothing, medication and vehicles were volunteered from all segments of society. Central government acted speedily to set up relief and rescue operations. The feeling of nationhood was strong in the face of the disaster and led to a surreal moment in Sri Lankan history. Underlying the success of the immediate rescue and relief operations was the strong culture of extended family, informal community support networks and charity. However, the government's disregard of this connected social infrastructure, and preferences for 'tool kit' approaches to recovery and reconstruction, and foreign donor involvement would later undermine the rebuild [6].

\subsection{Governance and leadership}

The attitude of the Sri Lankan government towards the rebuilding of the nation was predominantly paternalistic. It was informed by a local culture of charitable assistance for affected communities and recognition of the development opportunity presented by the disaster. Both attitudes pursued the typical paternalistic approach of 'we know what's best'. This led to a failure on the part of government to recognize the needs and capacities of affected communities, particularly the rural culture of self-reliance shaped by a protracted civil war and traditional livelihoods based on community networks, and to include them in the rebuilding of their lives and communities [6]. Within two days of the tsunami and with cross party support, the government set up three task forces, and created government agencies with funds and the power to disperse these for relief efforts [7]. Each task force had a clear role. The first was to focus on rescue and relief (TAFRER) and the second on logistics, law and order (TAFLOL). These were to be united at the end of the relief and rescue period as the Task Force for Relief (TAFOR) responsible for relief packages for assisting with long term recovery. The third was the Task Force for Rebuilding the Nation (TAFREN) which within twenty days of establishment released its initial plan of action, to 'build back better' and provide a $50 \mathrm{~m}^{2}$ house including all amenities to everyone whose home was destroyed or damaged beyond repair and relocated out of the newly imposed 100-200m no-build coastal buffer zone [7]. TAFREN then advised that a committee of experts from the government and the private sector had already prepared type plans for the houses and land for relocation had been identified [7]. 
This was a massive undertaking for any government, especially that of a developing nation, considering that over 110,000 houses had been damaged or destroyed, 70,000 new houses were needed and over 50,000 families had to be relocated [8]. In addition, the government had the task of rebuilding damaged public infrastructure, including hospitals and schools, and ensuring the quick recovery of the tourism industry, a key generator of much needed income. To achieve its ambitious goals, the government enlisted the support of over 500 local and international NGOs [8] and the corporate sector, with 156 aid organizations pledging to provide houses [7]. By May 2005 US\$ 2.2 billion was pledged for the following three years of recovery.

Any rebuilding effort requires a thorough knowledge of the country, its people and its institutional structures to succeed. As a diverse, multi-cultural country with considerable geographic diversity, Sri Lanka presents a complex situation to plan and build for. The close-knit, extended family structure has provided a valuable support system and has assisted in the rebuilding of lives after disasters for generations. With a population of 19 million at the time, Sri Lanka had access to a significant labor force; particularly as the civil war and the 'war economy' had led to deterioration of rural communities, rural industries and infrastructure. The local construction industry was manual labor dependent. Local conditions were well suited for increasing employment opportunities and supporting the growth of village and local economies. In this respect, the Tsunami presented an ideal opportunity to rebuild the nation.

The success of the initial relief response gave momentum for the next phase; the building of permanent housing. However, with the generous flow of aid and humanitarian support a centralized system of administration began to emerge. Tensions between stakeholders grew as political attempts to control the distribution of aid led to mistrust and challenged the fragile peace the tsunami had delivered. By December 2005 the civil war had resumed [6]. With a lack of clarity around the buffer zone $(100 \mathrm{~m}$ in some regions and $200 \mathrm{~m}$ in others), revisions to this policy created uncertainly about where boundaries stopped and started. In addition, the great haste with which reconstruction and relocation was progressing meant several communities had already been moved to poorly located new settlements several kilometers inland before the buffer zones were resolved [6]. Isolated by distance from extended family and community networks, livelihoods and public amenities due to the lack of infrastructure, vulnerabilities were aggravated. Building back better had not been interpreted by all as the opportunity to redevelop in ways that were culturally, environmentally and economically sustainable, utilizing local and foreign resources, strengthening local industry and working toward a long-term solution for reducing poverty. Some had seen it as an opportunity for rural regions to be modernized with new housing and public infrastructure developments in coastal cities and to support the recovery of the tourism industry. This approach failed to recognize the urgent needs of rural communities, the important relationship between place and traditional livelihoods and the infrastructure needed to maintain these.

\subsection{Housing and Community}

With little time given to considering what housing might mean or lessons learned from past mass housing programs in Sri Lanka, the plans developed by the experts responded strictly to the $50 \mathrm{~m}^{2}$ maximum house and minimum cost of construction. Beyond this, little consideration appears to have been given to cultural and contextual diversity, adaptability to suit individual needs, vernacular material and labor resource availability, and the likelihood of inflation, given that a nationwide rebuilding effort had been initiated with immediate effect. To aggravate the situation further, most donor organizations and those responsible for the design of housing had little prior association with the client communities or experience in housing, community and rural development in Sri Lanka [9]. Observing this, the founder of Sri Lanka Solidarity stated that 'it should not be a matter of just putting people into houses in empty paddocks but of thinking how these communities might be operating in 10 or 20 years' time' [9]. Paul Oliver had expressed similar sentiments decades earlier when he observed the housing that had been built for rural communities after the 1970 Gediz earthquake in Turkey. He believed such interventions were 'predicated on the belief that the victims of a disaster should be provided with housing as they may be provided with medicines, blankets or food' [10]. This also reflects a widespread belief that housing is a 'quick fix' to the problem of poverty and vulnerability without recognition of the complex physical and psychological dynamics between rural people, their homes, and livelihoods. According to Oliver, this understanding of housing 'is largely based on the concept of the dwelling as a consumer product and marketable commodity' [10], hence the naïve perception that housing provides evidence of development. In addition, 
these forms of development assume separation of owner, designer and builder, thereby failing to recognize the intricate relationships that inform the homes of these communities and the capacity of traditional rural communities to shape their living environments [10].

The first response of communities after moving into new houses was to add shade structures to compensate for their short eaves, which provided no respite from the intense heat and tropical showers [11]. Ancillary structures were added using salvaged and vernacular materials for kitchens as those provided were inadequate for traditional food preparation and cooking methods [11]. More complex spatial needs based on cultural practices, traditional beliefs and livelihood functions were more difficult to fix and the psychological effect of this was demoralizing for communities [11]. It was clear the basic house types developed by local experts and sometimes modified slightly by donor organizations failed to meet even the most basic needs related to climatic conditions and comfort [11].

The communities most affected by relocation and unsuitable housing were the traditional coastal fishers, a community dependent on location, extended family and community networks for their livelihoods. Relocation meant breaking up the intricate social and livelihood networks, particularly as community members beyond the no-build zone had to remain where they were $[6,11,12]$. The negative outcomes of relocation were seen a few years later when communities unable to maintain their traditional livelihoods abandon these, leading to unforeseen employment issues. Several families opted to move back to their original settlements for livelihood purposes [9] having abandoned or sold their new homes.

\section{The Christchurch Recovery}

With three significant events and more than 10,000 recorded aftershocks, the Christchurch earthquakes in the period 2010-11 are now more commonly referred to as a seismic sequence. The most serious event took place on February 22, 2011 and led to 185 deaths. Following this, large tracts of the city's central area were closed to the public for more than a year to facilitate demolition of more than 1,300 commercial buildings, and to make way for the recovery. As in many other countries unexpectedly struck by disaster, New Zealand had no standing strategy for recovery, a situation that from the outset led to creation of new strategies and procedures around recovery [13, 14]. Significant areas to the east of the city's central area were declared unfit to build on, belying the fact the city was founded on what is effectively a drained swamp [15-17]. As the affected areas have mostly been used for residential purposes this put additional pressure on housing markets. It quickly became clear that a significant and concerted effort would be needed to reinstate the city.

\subsection{Governance and leadership}

The first quake had mainly affected areas to the west of the city and plans for this recovery were progressing quickly and confidently at local government level. However, once the damage sustained in the February 2011 quake had been assessed, central government established the Christchurch Earthquake Recovery Authority (CERA) as it became clear that local government resources would be inadequate [17]. Although CERA's role was overarching, it also recognized the benefits of local expertise, if only in order to get through the work in a timely fashion. Council officers consulted widely, listened to public input and involved international expertise to develop the Draft City Plan. The highlight of this process was the Share an Idea campaign, which generated more than 100,000 recommendations for how the public would like to see the city reconfigured [17]. This consultation was also the catalyst for ideas such as lower central area building heights and green (environmental) initiatives that found their way into the Draft City Plan. However, this division of responsibilities led to poor coordination between the different plans, both in terms of philosophy and tangible proposals [18]. CERA continued to push for residential development around the city's ever expanding periphery, an objective that conflicted with the council's plan for a more compact and vibrant city center, supported by housing within walking distance of it and of local centres.

Following the consultative process that led to the Draft City Plan, CERA finalized it and relaunched it as the Recovery Plan through a top-down exercise, a bureaucratic process that continues to attract considerable negative criticism $[16,19]$. It has subsequently been noted that CERA was both incapable and unwilling to engage the public effectively [20]. Swaffield [19] was much more cynical in his analysis. He suggested that the centralized form of decision-making suited the government's longer term ambitions of clawing decision-making and development 
regulation back from local government. For more than a century and until economic liberalism spread to New Zealand in the 1980s and 90s, activities throughout the country had been closely and centrally managed. However, progressive devolution of responsibilities to local government over the ensuing 25-year period led to circumstances that frustrated national agendas, such as infrastructure development. Government had therefore been making efforts to return power to itself and the earthquakes simply provided the opportunity to make this happen more quickly under the guise of a rebuild.

As part of their commitment, the government would contribute NZ\$5.5 billion toward the rebuild, with the majority of this allocated to land remediation and to purchase of properties in areas determined as unfit for rebuilding [15]. The fund was also called on to rebuild state owned assets and essential infrastructure. In all other respects, it was expected that the recovery would be market led. New Zealand's central and local governments lack resources to contribute funding for rebuilding on private land, which other larger economies can often provide following disaster. Instead, the government sought to attract new overseas investment into New Zealand and otherwise expected private rebuilding costs to be met by insurance company payouts [16]. With one of the highest rates of insurance cover internationally it was widely expected that this would be the fastest and most equitable means of funding reconstruction [21, 22]. However, with reconstruction so heavily dependent on insurance, the slow pace of settlement and other uncertainties around payments have substantially slowed the progress and effectiveness of the recovery [23].

Public perceptions of the way the recovery has been managed to date are very poor, with up to $80 \%$ of the people living in Christchurch holding a negative view [20]. While the recovery has been characterized in media and NGO reports as slow, the government's own accounts of progress have been very different. CERA's communications appear to have been directed at those living outside the city, perhaps hoping to encourage investment or other forms of patronage to Christchurch. They may also have been naïve attempts to placate residents. However, appropriate and accurate communication is considered a key success factor for recovery processes [2], a fact that seems to have bypassed the government and which has led to many negative public perceptions of these.

\subsection{Housing and community}

To date housing has received very little attention in Christchurch's recovery. While the Recovery Plan anticipates people will live in the central area, only a few small projects around the edges have so far emerged from private initiatives. CERA, and its successor organization Ōtākaro Ltd, have remained unwilling to incentivise residential development within the core area, preferring to let market forces dictate what gets built. This is evidenced by the failure of a high profile, inner city residential development to proceed because it could not be made economically viable. Identified as a housing demonstration project in the Recovery Plan, it was meant as a catalyst for further high quality, medium density residential development around it. The government has been roundly criticised for its role in this failure. The land had been acquired at a depressed valuation through compulsory purchase and yet exceeded the preferred developer's current market value for it [24]. An alternative approach could have been to work with private developers to influence the type and quality of development through the land transaction.

While the actual numbers of units this project would have provided are small in the context of the overall need, the case also highlights the difficulties of creating housing where demand is largely being met by greenfield development around the edges of the city. Pressures to build outward were certainly strong prior to 2010 and in the aftermath of the earthquakes this has only increased in pace, encouraged by a government eager to be perceived as enabling of development $[19,25]$. Not only do these practices continue to compromise other intended outcomes, such as creating better public transport infrastructure and adding vitality to the city center, but development around the edges also attracts investment that could otherwise be directed to the more difficult brownfield projects within walking distance of the city center. The effects of this are only compounded by a current crisis around housing supply and affordability at the national scale [26].

\section{Discussion and conclusions}

The cases of Christchurch, New Zealand and Sri Lanka present very different examples of disaster recovery context and approach. Sri Lanka is considered to be an emerging economy, a classification that is made more obvious when comparisons are made with New Zealand. Disasters are of course oblivious to such distinctions and leadership must 
respond to develop strategies for recovery with what is available. In Sri Lanka's case, a number of international aid organizations provided important physical and financial support, not only during rescue and relief but also to assist ongoing recovery efforts. On the other hand, very little funding for the recovery of Christchurch was made available by aid agencies. The two different circumstances led to different opportunities and constraints.

Sri Lanka's government was responsive to the expectations that accompanied incoming financial and other resources, which led to decisions being taken quickly through bureaucratic agencies with little direct input from local communities. Faced with a mammoth rebuilding task, government decision-making processes and the circumstances around funding enabled the recovery to proceed at speed. The government took on a considerable challenge when it decided to build 70,000 houses for those displaced by the tsunami and subsequently imposed the controversial 'no build zones'. This challenge was addressed by entrusting this work to donor organizations. These organizations were invited to create the much-needed housing and to develop communities normally without the requisite experience or accountability. Taking this risk was an important step in enabling the government to deliver on its promises. Nevertheless, the ensuing bureaucratic controls on aid distribution came to hinder progress as the recovery wore on. This can be compared with the Christchurch recovery, which has been slow to take hold as a consequence of funding difficulties and by the painstaking, but necessary, redevelopment of essential infrastructure. Government actors have taken no active financial responsibility for recovery on individual sites, yet helped create a context of uncertainty and bureaucratic inefficiency that stifled redevelopment activity for several years.

\subsection{Local responsiveness}

The Christchurch and Sri Lanka cases reveal tendencies toward central bureaucracy, and the negative effects these can have when not balanced with input from grass root sources. Government agencies in both countries came in above the local activities that had commenced soon after each disaster struck. Examples of social resilience, which emerged around people's desire to rebalance their lives after a disruptive event, were effectively squashed by the respective bureaucracies. The top down approaches are not ideal, particularly as they do not provide opportunity for community participation and engagement in vital decision making. Community participation in development processes is important even though these methods alone will not lead to good governance. Schilderman [27] considered participatory methods should be supported by a combination of government and stakeholder actions in order to properly address people's needs.

In both cases, global approaches to design and building have been privileged at the expense of locally developed patterns and processes and this seems to lie behind a number of subsequent problems. In Sri Lanka, this was played out through inappropriate forms of housing and urban design. While longer term impacts of donor built housing and communities are yet to be determined, the more immediate outcomes were general frustrations with housing quality evidenced by the lack of suitability for cultural needs and distance to sources of livelihood. Efforts by communities to adapt their new living environments provide further evidence of resilience found at personal levels. Determined to make the best of their situations, they utilized vernacular construction methods and organized themselves to assist each other in making their living environments more humane. They became proficient at adapting to their new situations. Communities that returned to their original environments were willing to risk future tsunamis and to lose essential donor assistance. People voted with their feet in declaring preferences for their communities, networks and connections to place. Providing for continuity of livelihoods and for starting up new livelihoods is essential for a successful recovery and should be a priority in post disaster planning.

Evidence of a lack of locally responsive decision-making can also be found in many aspects of the Christchurch recovery. The top-down process that led to the Recovery Plan took place behind closed doors after a very promising foundation had been laid through consultation by local government. Not only were many of the grassroots ideas dispensed with in the CERA plan but the process created dissatisfaction amongst those for whom the city was being replanned. The emerging character of the city, as it is rebuilt according to the plan, has little in common with the character that was developed by early settlers working with local materials and in response to local environmental conditions. Although this distinctive character had been somewhat eroded by insensitive development during the previous 30 years, none of that fabric now remains to connect people with the city's past.

Projects that are being built at unprecedented physical scale, incorporating internationally sourced design language and materials, speak more to economic efficiencies than to sense of place. In the process, small businesses have been 
marginalized in the wake of government approaches that favor large scale development. This fixation on economies of scale can be seen through requirements for minimum site area $\left(10,000 \mathrm{~m}^{2}\right)$ in the core area with the additional requirement that adjoining landowners work together when sites fall short. Although development can be expected to respond to socio-economic factors, it is clear that higher socioeconomic demographic groupings are being privileged in and around the central area. There is a lack of affordability and so the diversity that had been a characteristic of the city and its fringes prior to the earthquakes has been lost. This outcome, linked to land costs and contemporary development models, has been allowed to emerge in the absence of local responsiveness by government leaders.

\subsection{Balancing short term gains with long term needs}

Leaders of both recovery efforts came quickly to realize the great opportunity the circumstances provided for improving the places most affected by these natural disasters. Neither case could be seen to have shied away from the opportunity to build back better, but each appears to have fallen short of doing so, constrained perhaps by decisions made around short term gains. There can be little doubt that traditional forms of infrastructure have been replaced and refurbished with longer horizons in mind. However, less obvious aspects of the recoveries have failed to be treated with the same vigour. In both cases, areas of housing were created without appropriate attention being given to people's needs or to the strategies underpinning the recovery plan. As demonstrated in the case of Sri Lanka, there has been a lack of accountability which has contributed to wastage of valuable resources at all levels and failed to ensure the suitability of outcomes. It is somewhat disturbing that communities have been left to resolve these shortcomings themselves and in this sense, the initial efforts have not contributed to a reduction in long term vulnerability.

With a focus on getting the recovery of the central area under way, CERA adopted a recovery plan that dispensed with key public transport, urban form and building performance initiatives that had been highlighted in earlier stages. It seemed that these proposals, informed at local level and by international experts, were placed in the too-hard basket by a government intent on stimulating action. In this context, the time it would have taken to plan and implement the innovative transport plan and uncertainties around funding were the enemy. The status quo before the earthquakes, including antiquated one-way roading systems, are what the plan eventually fell back on. It has also been noted that opportunities to enable housing to be located closer to the city center have been compromised by the ongoing release of land around the city's perimeter. While the success of the Recovery Plan relies on creation of a robust and thriving inner-city population of residents, developer confidence to create such housing keeps being diminished by the steady development of suburban areas, and this despite a current national crisis in housing supply. Disappointingly, the chance to create something innovative will be left to following generations.

\subsection{Recommendations and conclusion}

In order to overcome the noted process deficiencies, leaders should consider minimizing the distances between central government and the local context. While central government can often provide economic and political weight to recovery efforts, on the evidence of these two cases they appear to be unable to sense the local setting and aspirations of residents. Achieving this is going to be much easier said than done, as some levels of bureaucracy will be necessary to provide organizational legibility, efficiency and accountability. Recovery efforts should aim to create a better balance between economic, cultural, environmentally sustainable and diversity motivations. Finally, communication channels must be kept open and vital. A key frustration for people in the Sri Lanka and Christchurch recovery zones has been with communication. Two-way communications were found to be limited, largely by government agencies that have been more eager to tell positive stories about the recovery to national and international audiences than they have been to listen to residents' concerns. Unfortunately, the failure of government leaders to communicate appropriately with citizens during rebuilding processes is not uncommon [2]. However, as this shortcoming is so well known and as communication practices are increasingly flexible and responsive, overcoming this is entirely within the control of those who lead recoveries. 


\section{References}

[1] Chang, S., Urban disaster recovery: a measurement framework and its application to the 1995 Kobe earthquake. Disasters, 2010. 34(2): p. 303327.

[2] Olshansky, R.B., L.A. Johnson, and K.C. Topping, Opportunity in chaos: rebuilding after the 1994 Northridge and 1995 Kobe earthquakes. 2005, University of Illinois: Urbana-Champaign, USA. p. 373 p.

[3] Bowen, P.A., et al., Perceptions of Time, Cost and Quality Management on Building Projects. 2012, 2012. 2(2): p. 9.

[4] Quarantelli, E., Community Response to Disasters, in Disaster and Mental Health: Selected Contemporary Perspectives, B.T. Showder, Editor. 1985, National Institute of Mental Health: Rockville, MD. p. 122-136.

[5] Riad, J. and F. Norris, The Influence of Relocation on the Environmental, Social, and Psychological Stress Experienced by Disaster Victims. Environment and Behavior, 1996. 28(2): p. 163-182.

[6] Samaratunge, R., K. Coghill, and H. Herath, Governance in Sri Lanka: Lessons from Post-Tsunami Rebuilding. Journal of South Asian Studies, 2012. 35(2): p. 381-407.

[7] Tittawella, M., Rebuilding Sri Lanka Post Tsunami. 2005: ADB Manila Summit.

[8] Bank, W. Implementation Completion and Results Report to the Democratic Socialist Republic of Sri Lanka For a Tsunami Emergency Recovery Program. 2009; Available from: https:/www.gfdrr.org/sites/default/files/documents/Sri Lanka - 2004 Indian Ocean Earthquake Tsunami Emergency Recovery Program - ICR.pdf.

[9] Shaw, J., et al., Lessons from Tsunami Recovery in Sri Lanka and India. 2011, Community, livelihoods, tourism and housing. : http://artsonline.monash.edu.au/mai/files/2012/06/post-tsunami-1.pdf.

[10]Oliver, P., Rebirth of a Rajput Village. Traditional Dwellings and Settlements Review, 1992. 3(2): p. 13-21.

[11]De Sylva, S.D. House Step Garden Shore Sea: Contested Thresholds of Fisher Dwelling. in Society, Architects, and Emerging Issues: 18th Commonwealth Association of Architects. 2008. Dhaka: CAA and Bangladesh Institute of Architects.

[12]Birkmann, J. and N. Fernando, Measuring revealed and emergent vulnerabilities of coastal communities to tsunami in Sri Lanka. Disasters, 2008. 32(1): p. 82-105.

[13]Rotimi, J., J.L. Masurier, and S. Wilkinson, The regulatory framework for effective post-disaster reconstruction in New Zealand, in First International conference on Post-disaster Reconstruction: Meeting Stakeholder Interests. 2006: Florence, Italy.

[14]Myburgh, D., S. Wilkinson, and E. Seville, Post-disaster reconstruction research in New Zealand: an industry update. 2008, Resilient Organisations. p. 36.

[15]Brownlee, G., Draft recovery strategy for greater Christchurch, Canterbury Earthquake Recovery Ministry, Editor. 2011, New Zealand Government: Wellington.

[16]Bennett, B., et al., eds. Once in a lifetime: city-building after disaster in Christchurch. 2014, Freerange Press: Wellington. 512.

[17]Brand, D. and H. Nicholson, Public space and recovery: learning from post-earthquake Christchurch. Journal of Urban Design, 2016. 21(2): p. 159-176.

[18]Gjerde, M., Sure to rise? . International Journal of the Constructed Environment, 2012.

[19]Swaffield, S., Place, culture and landscape after the Christchurch earthquake, in Space, Place \& Culture, Anon, Editor. 2013, Future Leaders: http://www.futureleaders.com.au/book_chapters/Space-Place-Culture/Simon-Swaffield.php. p. 1-26.

[20]Simons, G., Projecting failure as success: Residents' perspectives of the Christchurch earthquakes recovery. Cogent Social Sciences, 2016. 2016(2): p. 1-22.

[21]Comerio, M.C., Disaster recovery and community renewal: Housing approaches. Cityscape: A Journal of Policy Development and Research, 2014. 16(2): p. 51-68.

[22]Kamel, N.M.O. and A. Loukaitou-Sideris, Residential assistance and recovery following the Northridge earthquake. Urban Studies, 2004. 41(3): p. $533-562$.

[23]Mackenzie, A., Christchurch rebuild. Build, 2011. 126(-): p. 34-40.

[24]Stylianou, G., Gerry Brownlee denies blame for failed Breathe residential project in Stuff. 2016, Fairfax Media: Christchurch.

[25]Salmon, G., Christchurch, in Drivers of Urban Change, L. Early, P. Howden-Chapman, and M. Russell, Editors. 2015, New Zealand Centre for Sustainable Cities: Wellington. p. 134-171.

[26]Early, L., P. Howden-Chapman, and M. Russell, eds. Drivers of Urban Change. 2015, New Zealand Centre for Sustainable Cities: Wellington. 272.

[27]Schilderman, T., Putting people at the center of reconstruction, in Building Back Better, Delivering people-centered housing reconstruction at scale, M. Lyons, T. Schilderman, and C. Boano, Editors. 2010, Practical Action Publishing Ltd.: UK. p. 7-36. 